\title{
INFLUENCE OF THE SURGICAL CLIP ON BREAST, HEART AND LUNG VOLUMES OF PATIENTS SUBMITTED TO BOOST DURING THE PLANNING OF BREAST CANCER RADIOTHERAPY, ACCORDING TO ONCOPLASTIC SURGERY
}

Priscila D. Watanabe1, Nilceana M. A. Freitas'2,3, Marcus N. Borges¹, Edésio Martins', Thais F. Simionatto², Nathalya A. Yagi², Ana Flávia P. G. Campedelli², Ruffo Freitas-Junior ${ }^{1,2}$

${ }^{1}$ CORA - Centro Avançado de Diagnóstico da Mama, Hospital das Clínicas, universidade Federal de Goiás - Goiânia (GO), Brazil. ${ }^{2}$ Hospital Araújo Jorge, Associação de Combate ao Câncer de Goiás - ACCG - Goiânia (GO), Brazil.

${ }^{3}$ Centro Brasileiro de Radioterapia Oncologia e Mastologia - Goiânia (GO), Brazil.

Objectives: To evaluate the breast, heart and lung irradiated volumes considering the presence of clip implantation in breast tumor bed boost during radiotherapy, according to the use of oncoplastic surgery. Methodology: Women submitted to boost radiotherapy tumor bed after breast conservative surgery for breast cancer patients between 01/201104/2018. Statistical analysis using Student T Test (95\%CI; $\mathrm{p}<0.05)$. It was considered volumes of lung and heart relative to $40 \%$ of prescribed dose in the boost radiation planning (V40Lung) (V40Heart) and $100 \%$ in the breast and boost volume (V100Breast) (V100Boost), which were compared by oncoplastic techniques and surgical clips using the dose-volume histogram (DVH) in 3D dose distributions radiotherapy. Results: 149 patients, of whom 71 had clip (48\%). Of the 69 patients submitted to oncoplasty, 38 had clip in the surgical bed (55\%). For the whole group, when the patient was clipped there was a difference between the mean volume V100Boost $=110 \mathrm{~cm}^{3}(\mathrm{PD} \pm 37)$ and without clip V100Boost $=213 \mathrm{~cm}^{3}(\mathrm{PD} \pm 208)$ $\mathrm{p}<0.001$, but there was no difference for V100Breast $=282 \mathrm{~cm}^{3}$ with clip (PD \pm 141$)$ and without clip V100Breast $=400 \mathrm{~cm}^{3}$ (PD \pm 188$) \mathrm{p}=0.085$, nor for V40Lung $=57 \mathrm{~cm}^{3}(\mathrm{PD} \pm 41)$ with clip and $43 \mathrm{~cm}^{3}(\mathrm{PD} \pm 47) \mathrm{p}=0.72$ and V40Heart $=2.40 \mathrm{~cm}^{3}(\mathrm{PD} \pm 6)$ with clip and $2.78 \mathrm{~cm}^{3}(\mathrm{PD} \pm 14) \mathrm{p}=0.59$. For those who underwent oncoplasty, there was no difference between the means of the volumes analyzed according to the presence of the clip. However, for those who did not undergo oncoplasty only the V40Lung was not significant for the presence of the clip ( $\mathrm{p}=0.28)$, but were significant for V100Boost $=111 \mathrm{~cm}^{3}(\mathrm{PD} \pm 35)$ with clip and $262 \mathrm{~cm}^{3}(\mathrm{PD} \pm 274)$ without clip ( $\left.<<0.001\right)$, V100Breast $=306 \mathrm{~cm}^{3}(\mathrm{PD} \pm 147)$ with clip and $423 \mathrm{~cm}^{3}(\mathrm{PD} \pm 218)$ without clip ( $\mathrm{p}=0.002)$ and V40Heart=2.02 $\mathrm{cm}^{3}(\mathrm{PD} \pm 4)$ with clip and $0.62 \mathrm{~cm}^{3}(\mathrm{PD} \pm 2)$ without clip $(\mathrm{p}=0.009)$. The most commonly used oncoplastic techniques were reduction mammoplasty in 23 patients $(33 \%)$ and round block in 8 (12\%). Conclusion: The presence of the clip significantly reduced the irradiated boost volume. When controlled by oncoplasty, there was no difference between groups. For those who did not undergo oncoplasty, the presence of the clip made it possible to reduce the irradiated volume that received $100 \%$ of the prescribed dose of the whole breast and the boost area, but increased the cardiac volume that received $40 \%$ of the prescribed dose during the radiotherapy boost planning. 